\title{
Unusual complication of stent placement in the treatment of coarctation
}

\author{
Serhat Koca ${ }^{*}$, Ayşenur Paç ${ }^{1}$, Vedat Kavurt ${ }^{2}$, Ajda Mıhçıoğlu ${ }^{3}$, Denizhan Bağrul ${ }^{1}$ \\ ${ }^{1}$ Department of Pediatric Cardiology, Yuksek Ibtisas Heart-Education and Research Hospital, Ankara, Turkey \\ ${ }^{2}$ Department of Pediatric Cardiology, Diyarbakir Children Hospital, Diyarbakir, Turkey \\ ${ }^{3}$ Department of Pediatric Cardiology, Sadi Konuk Education and Research Hospital, Istanbul, Turkey
}

\begin{abstract}
Stent placement is the first line treatment for coarctation of aorta in adolescent and adult patient population. Complications during this procedure due to aortic wall and the technique were reported previously. Here we present a pediatric patient who developed a complete AV (atrio-ventricular) block during stent implantation which required temporary cardiac pacemaker and anti-inflammatory therapy.
\end{abstract}

Key Words: Coarctation of aorta, Complete atrioventricular block, Stent implantation

\section{Introduction}

Aortic balloon angioplasty and stent implantation has been used for treatment of coarctation of aorta (1,2). However, nowadays, stent implantation is being used as the first line treatment of coarctation of aorta in adolescent and adult patients (3). Complications due to aortic wall (intimal tear, aortic rupture, aortic aneurism) and technical issues (stent migration, balloon rupture, peripheral vessel damage) were previously reported (3). To our knowledge, complete atrioventricular block has not been reported as a complication during stent implantation to coarctation of aorta. Here we present a pediatric patient who developed a complete AV (atrioventricular) block during stent implantation which required temporary cardiac pacemaker and antiinflammatory therapy.

\section{Case report}

A 9 year-old girl with MVP (mitral valve prolapse) who was referred to our hospital with coarctation of aorta that is diagnosed during her regular follow-up echocardiography. During her physical examination, both femoral pulses were found weak and blood pressure measured from the lower extremity $(96 / 58)$ was detected lower than the upper extremity (150/100). Echocardiography revealed an aortic coarctation causing systolic maximum $60 \mathrm{mmHg}$ gradient due to stenosis at 8 $\mathrm{mm}$ distal from proximal end of subclavian artery. Catheter angiography was planned for stent implantation, after confirming the coarctation of aorta with MRI (magnetic resonance imaging) angiography (Figure 1). Systolic peak to peak gradient was $80 \mathrm{mmHg}$. Aortic diameters were measured as 5.7, 10 and $13 \mathrm{~mm}$ at narrowest point, proximal point of coarctation and descending aorta, respectively. Stent implantation to coarctation aorta was planned. First, a 0.35 inch sized extra stiff guide was placed to left subclavian artery but it could not be stabilized there and fall in to ascending aorta. Then, a guide was placed to left ventricle and a covered stent at $22 \mathrm{~mm}$ length were planted to the coarctation site by a balloon in balloon at $14 \mathrm{~mm} / 2.5 \mathrm{~cm}$ size. Peak to peak gradient between proximal and distal ends of coarctation was measured as $0 \mathrm{mmHg}$ after procedure (Figure 2, 3).

Complete AV block developed during stent implantation to patient (Figure 4) that required a temporary cardiac pacemaker. Patient was treated with $1 \mathrm{mg} / \mathrm{kg}$ dexamethasone and $80 \mathrm{mg} / \mathrm{kg}$ aspirin administration daily. At second day occasional $\mathrm{P}$ wave conduction to QRS wave on ECG (electrocardiogram) was detected. Patient was temporarily paced until normal sinus cardiac rhythm was detected at $9^{\text {th }}$ day of treatment. Patient was discharged home and now is being followed at outpatient clinic without any problem. 


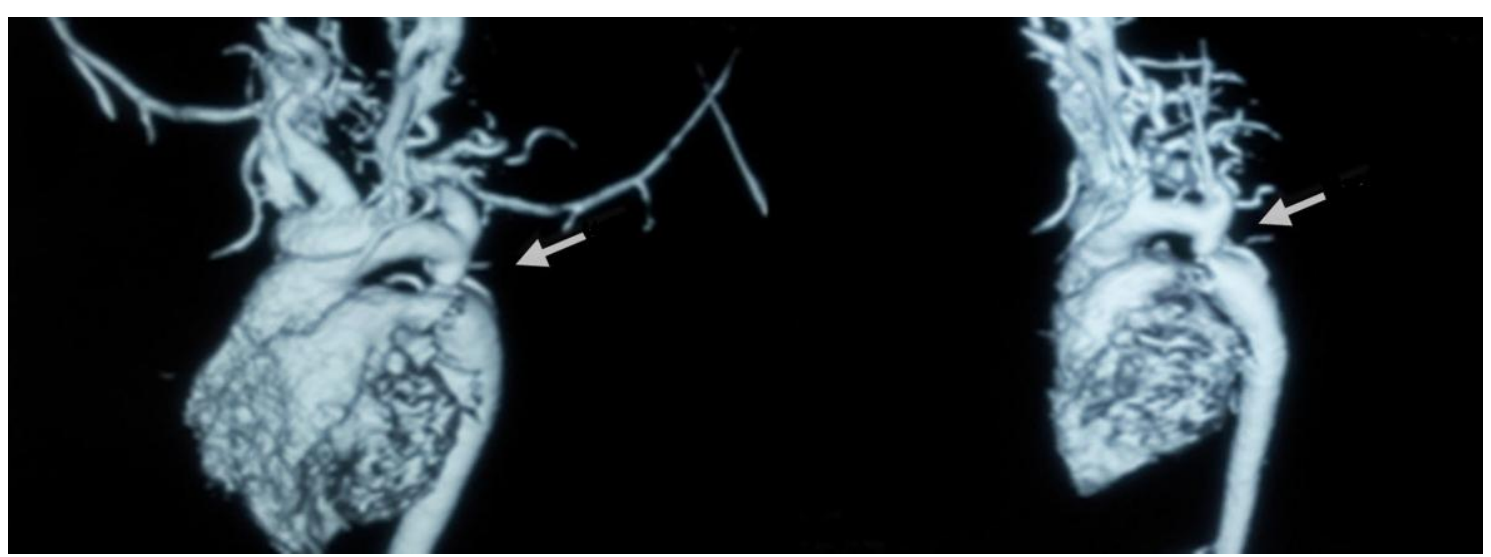

Fig. 1. MRI- Angiography showing coarctation at $8 \mathrm{~mm}$ distal from proximal end of subclavian artery.

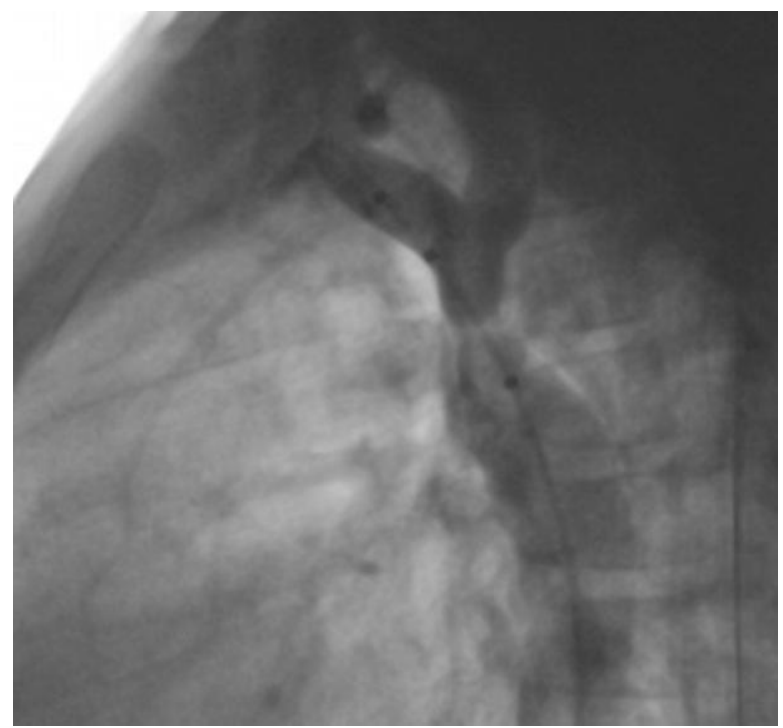

Fig. 2. Aortography before stent implantation.

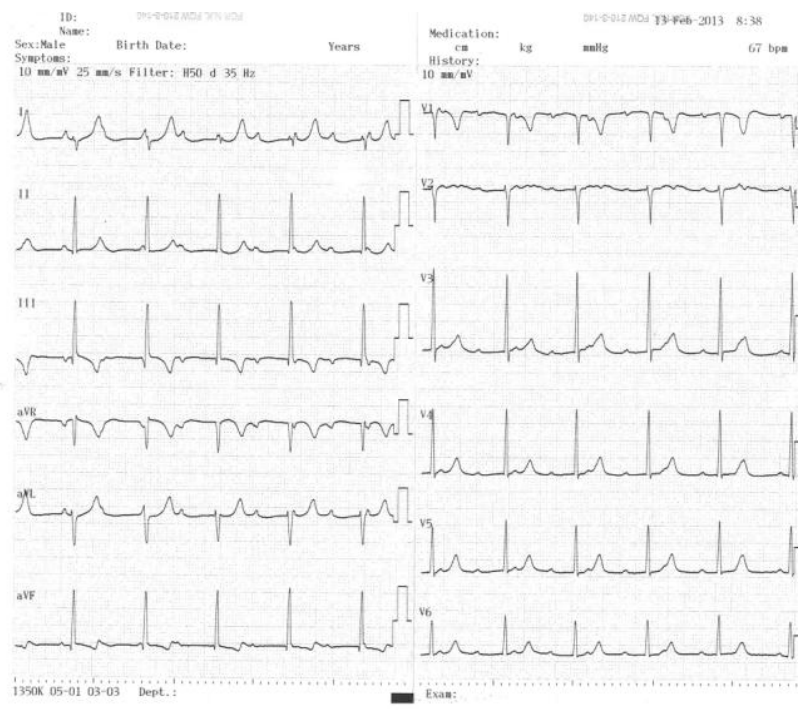

Fig. 4. Complete AV Block with narrow QRS that developed during stent implantation.

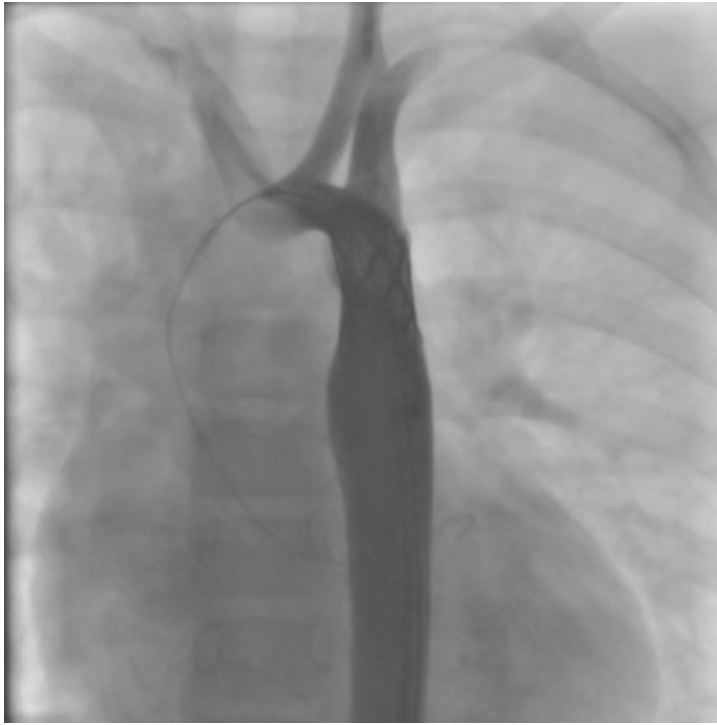

Fig. 3. Antero-posterior view of the patient and aortography after stent implantation.

\section{Discussion}

Although stent implantation has satisfied results in treatment of coarctation of aorta, there may be some complications during this procedure. In a large study with 565 patients from 17 different institutions; complications due to aortic wall (intimal tear, aortic rupture and aortic aneurism) and technical issues (stent migration, balloon rupture, peripheral vessel damage) were reported as $3.7 \%$ and $12.1 \%$, respectively (4).

Development of complete AV block as a complication is more commonly observed during closure of ASD (atrial septal defect) or VSD (ventricular septal defect) using device. Damages to AV conduction structure caused by discs of intra-cardiac device or edema developed at conduction tissue are accepted as the reasons of this complication (5-10). 
Various anti-inflammatory treatment modalities are suggested for treatment of complete AV block that developed during cardiac invasive procedures. One modality is suggesting 1 week administration of Prednisolone $(2 \mathrm{mg} / \mathrm{kg} / \mathrm{d}$ at 3 doses, $\max 80$ $\mathrm{mg} /$ day $)$ and Aspirin $(100 \mathrm{mg} / \mathrm{kg} / \mathrm{d}$ at 3 doses, $\max 2 \mathrm{gr} / \mathrm{day}$ ) that is followed by 2 more weeks of treatment at reduced doses (11). The other modality, which we followed in this case, Dexamethasone (1 $\mathrm{mg} / \mathrm{kg} /$ day for 2 weeks followed by another 3 weeks at reduced doses) and Aspirin $(80 \mathrm{mg} / \mathrm{kg} /$ day for 1 week, followed by reduced to anti-aggregating dose in 4 weeks and continued for another 6 months) are suggested (12).

In the presented case, despite not use of intracardiac device, traumatic effect of stiff fiber that is placed in to the left ventricle during implantation of aortic stent can be shown as the reason of development of complete AV block. We think that this effect can be circumvented by placing stiff fiber in to the ascending aorta or subclavian artery. In other words as this case shows us, stiff fiber placement in to the left ventricle should be avoided in order not to develop an AV block.

Acknowledgement: The authors declare that there are no conflicts of interest.

Statement of Human Rights: Informed consent for all the procedures were taken from the family of the patient. Formal consent was also obtained from the patient's family for purpose of publication without patient`s identitiy.

\section{References}

1. Crafoord C, Nylin G. Congenital coarctation of the aorta and its surgical management. J Thorac Cardiovasc Surg 1945; 14: 347-361.

2. Shah L, Hijazi Z, Sandhu S, Joseph A, Cao QL. Use of endovascular stents fro the treatment of coarctation of the aorta in children and adults: Intermediate and midterm results. J Invas Cardiol 2005; 11: 614-618.
3. Krasemann T, Bano M, Rosenthal E, Qureshi SA. Results of stent implantation for native and recurrent coarctation of the aorta-follow-up of up to13 years. Catheter Cardiovasc Interv 2011; 78: 405-412.

4. Forbes TJ, Garekar S, Amin Z et al. Congenital Cardiovascular Interventional Study Consortium (CCISC) Procedural results and acute complications in stenting native and recurrent coarctation of theaorta in patients over 4 years of age: a multi-institutional study. Catheter Cardiovasc Interv 2007; 70: 276-285.

5. Al-Anani SJ, Weber H, Hijazi ZM. Atrioventricular block after transcatheter ASD closure using the Amplatzer septal occluder: risk factors and recommendations. Catheter Cardiovasc Interv 2010; 75: 767-772.

6. Lin SM, Hwang HK, Chen MR. Amplatzer septal occluder-induced transient complete atrioventricular block.J Formos Med Assoc 2007; 106: 1052-1056.

7. Nakanishi T. Interventional catheterization. Curr Opin Cardiol 2000; 15: 211-215.

8. Wang JK, Tsai SK, Wu MH, Lin MT, Lue HC. Short- and intermediate-term results of transcatheter closure of atrial septal defect with theAmplatzer Septal Occluder. Am Heart J. 2004; 148: 511-517.

9. Zhou T, Shen XQ, Zhou SH, et al. Atrioventricular block: a serious complication in and after transcatheter closure of perimembranous ventricular septal defects. Clin Cardiol 2008; 31: 368-371.

10. Butera G, Gaio G, Carminati M. Is steroid therapy enough to reverse complete atrioventricular block after percutaneous perimembranous ventricular septal defect closure? J Cardiovasc Med (Hagerstown) 2009; 10: 412-414.

11. Yip WC, Zimmerman F, Hijazi ZM. Heart block and empirical therapy after transcatheter closure of perimembranous ventricular septal defect. Catheter Cardiovasc Interv 2005; 66: 436-441.

12. Erdem S, Kizlltaş A, Küçükosmanoğlu $O$, Ozbarlas N. Temporary atrioventricular complete block that develops following the transcatheter closure ofventricular septal defect. Turk J Pediatr 2012; 54: 80-82. 